\title{
ARTICLE
}

\section{Impact of active cancer on COVID-19 survival: a matched- analysis on 557 consecutive patients at an Academic Hospital in Lombardy, Italy}

\author{
Alexia F. Bertuzzi (iD) ${ }^{1}$, Michele Ciccarelli (iD) ${ }^{2}$, Andrea Marrari (D) $^{1}$, Nicolò Gennaro (D) $^{3,4}$, Andrea Dipasquale ${ }^{3,5}$, Laura Giordano ${ }^{6}$, \\ Umberto Cariboni ${ }^{7}$, Vittorio Lorenzo Quagliuolo ${ }^{8}$, Marco Alloisio ${ }^{3,7}$ and Armando Santoro (ID $^{1,3}$
}

BACKGROUND: The impact of active cancer in COVID-19 patients is poorly defined; however, most studies showed a poorer outcome in cancer patients compared to the general population.

METHODS: We analysed clinical data from 557 consecutive COVID-19 patients. Uni-multivariable analysis was performed to identify prognostic factors of COVID-19 survival; propensity score matching was used to estimate the impact of cancer.

RESULTS: Of 557 consecutive COVID-19 patients, 46 had active cancer (8\%). Comorbidities included diabetes ( $n=137,25 \%)$, hypertension ( $n=284,51 \%)$, coronary artery disease $(n=114,20 \%)$ and dyslipidaemia $(n=122,22 \%)$. Oncologic patients were older (mean age 71 vs $65, p=0.012$ ), more often smokers ( $20 \%$ vs $8 \%, p=0.009$ ), with higher neutrophil-to-lymphocyte ratio (13.3 vs $8.2, p=0.046)$. Fatality rate was $50 \%$ (Cl $95 \%$ : $34.9 ; 65.1)$ in cancer patients and $20.2 \%(\mathrm{Cl} 95 \%: 16.8 ; 23.9)$ in the non-oncologic population. Multivariable analysis showed active cancer $\left(\mathrm{HR}_{\text {active }}: 2.26, p=0.001\right)$, age $\left(\mathrm{HR}_{\text {age }}>65 y\right.$ years $\left.: 1.08, p<0.001\right)$, as well as

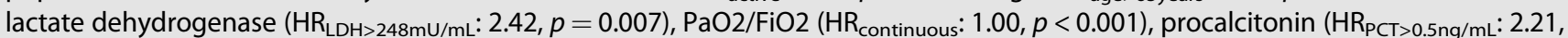
$p<0.001)$, coronary artery disease $\left(\mathrm{HR}_{\text {yes }}: 1.67, p=0.010\right)$, cigarette smoking ( $\left.\mathrm{HR}_{\text {yes }}: 1.65, p=0.041\right)$ to be independent statistically significant predictors of outcome. Propensity score matching showed a $1.92 \times$ risk of death in active cancer patients compared to non-oncologic patients ( $p=0.013$ ), adjusted for ICU-related bias. We observed a median OS of 14 days for cancer patients vs 35 days for other patients.

CONCLUSION: A near-doubled death rate between cancer and non-cancer COVID-19 patients was reported. Active cancer has a negative impact on clinical outcome regardless of pre-existing clinical comorbidities.

British Journal of Cancer (2021) 125:358-365; https://doi.org/10.1038/s41416-021-01396-9

\section{BACKGROUND}

Since the beginning of the COVID-19 pandemic, cancer patients have been regarded as a vulnerable population. ${ }^{1-4}$ Early data reported a near two-fold risk of Sars-CoV-2 infection, a complicated course of infection and a higher fatality rate compared to non-oncologic patients. ${ }^{4-8}$ However, detailed data on the extent of the oncologic disease and anti-cancer therapies at Sars-CoV-2 diagnosis were often scant. Later analyses suggested a downsised risk of infection in cancer patients. We previously reported the experience of a referral Cancer Center in the epicentre of the Italian outbreak, with only 17 cases of Sars-CoV-2 being diagnosed among 1267 cancer patients on active medical treatment. ${ }^{9}$ In line with initial clinical suggestions, we registered a higher COVID-19 fatality in oncologic patients compared to the general population. ${ }^{10-12}$ In this uncertain scenario, major oncological societies released position papers recommending extreme caution in the management of cancer treatment, focusing on the undefined risk of a medical therapy impacting on the immune system. ${ }^{3,13-15}$ The worldwide spread of Sars-CoV-2 infection imposed a tough challenge for medical oncologists bearing the responsibility to treat cancer, an equally fatal disease. ${ }^{16-21}$ Consequently, efforts have been conducted to optimise cancer therapy during the pandemic and to better identify the features of poor outcome of the infection in cancer patients. ${ }^{22,23}$ Some published studies analysed demographic and clinical characteristics in this subgroup of patients detailing comorbidities, specific laboratory findings as well as radiological imaging at Sars-CoV-2 diagnosis. ${ }^{24,25}$

As a Cancer and COVID-19 referral centre, we also collected the aforementioned variables on the whole population of infected patients admitted in our Institution during the most intense period of the pandemic. We retrospectively analysed in a multivariate model, and confirmed by a propensity score, the weight of some of the most important aspects recognised as a risk factor for Sars-CoV-2 outcome, focusing on active cancer. ${ }^{12,26,27}$

\footnotetext{
${ }^{1}$ Oncology Unit, Humanitas Clinical and Research Center-IRCCS, Rozzano, Italy; ${ }^{2}$ Respiratory Medicine Unit, Humanitas Clinical and Research Center-IRCCS, Rozzano, Italy;

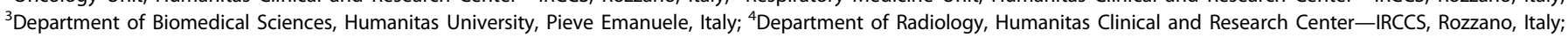

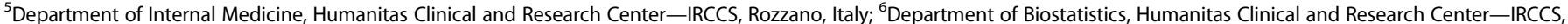

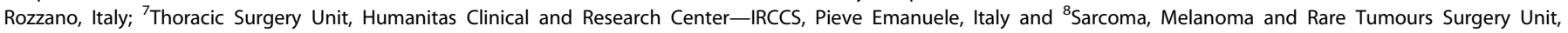
Humanitas Clinical and Research Center-IRCCS, Pieve Emanuele, Italy
}

Correspondence: Armando Santoro (armando.santoro@humanitas.it)

These authors contributed equally: Alexia F. Bertuzzi, Michele Ciccarelli

Received: 5 November 2020 Revised: 29 March 2021 Accepted: 9 April 2021

Published online: 11 May 2021 
Table 1. Overall and by cancer demographics and clinic characteristics of 557 hospitalised patients with COVID-19.

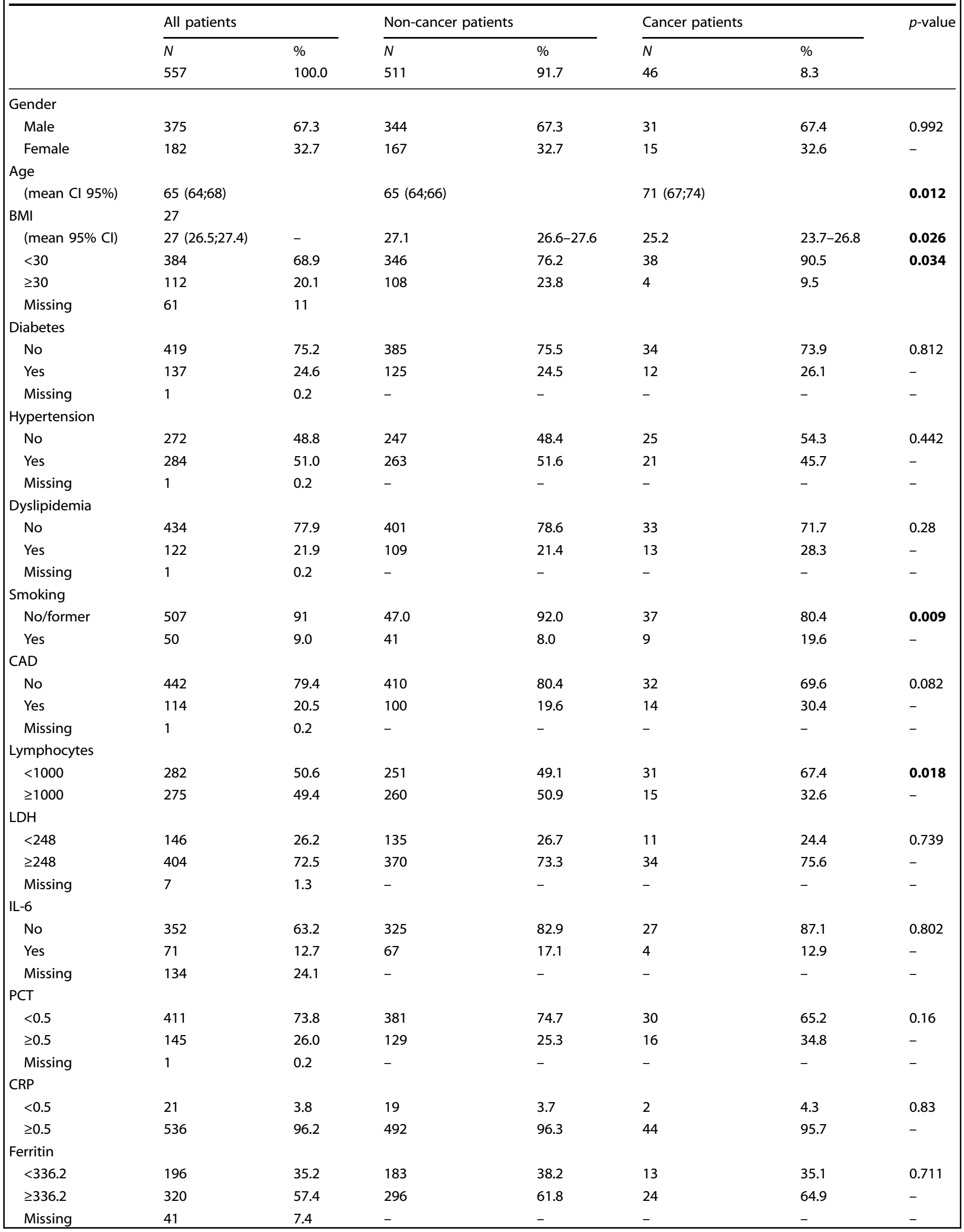




\begin{tabular}{|c|c|c|c|c|c|c|c|}
\hline & \multicolumn{2}{|l|}{ All patients } & \multicolumn{2}{|c|}{ Non-cancer patients } & \multicolumn{2}{|l|}{ Cancer patients } & \multirow[t]{2}{*}{$p$-value } \\
\hline & $N$ & $\%$ & $N$ & $\%$ & $N$ & $\%$ & \\
\hline \multicolumn{8}{|l|}{ NLR } \\
\hline (mean 95\% Cl) & 5.84 & $0.06 ; 85$ & 8.22 & $7.56 ; 8.89$ & 13.32 & $8.37 ; 18.26$ & 0.046 \\
\hline \multicolumn{8}{|c|}{ Ground glass opacities } \\
\hline No & 26 & 4.7 & 22 & 4.5 & 4 & 9.8 & 0.135 \\
\hline Yes & 504 & 90.5 & 467 & 95.5 & 37 & 90.2 & \\
\hline Missing & 27 & 4.8 & & & & & \\
\hline \multicolumn{8}{|c|}{ Pulmonary consolidations } \\
\hline \multicolumn{8}{|l|}{ Pleural effusion } \\
\hline No & 462 & 82.9 & 434 & 88.8 & 28 & 68.3 & $<0.001$ \\
\hline Yes & 68 & 12.3 & 55 & 11.2 & 13 & 31.7 & \\
\hline Missing & 27 & 4.8 & & & & & \\
\hline \multicolumn{8}{|c|}{ Pulmonary adenopathy } \\
\hline No & 375 & 67.3 & 345 & 70.6 & 30 & 73.2 & 0.723 \\
\hline Yes & 155 & 27.9 & 144 & 29.4 & 11 & 26.8 & \\
\hline Missing & 27 & 4.8 & & & & & \\
\hline
\end{tabular}

$C A D$ coronary artery disease, $B M I$ body mass index, $C I$ confidence interval, $L D H$ lactate dehydrogenase, IL-6 interleukin-6, $P C T$ procalcitonin, NLR neutrophil-lymphocyte ratio.

Statistically significant $p<0.05$ values are in bold.

\section{METHODS}

Study design

We retrospectively reviewed the medical records of all consecutive adult patients admitted for COVID-19 at our Institution (a tertiary cancer centre with 662 beds, including 42 ICU beds) between February 27 and May 20, 2020. The diagnosis of Sars-CoV-2 infection was confirmed by a reverse-transcriptase polymerase chain reaction (RT-PCR) of nasopharyngeal swab or bronchoalveolar lavage (BAL). We collected data on demographics, smoking habits and comorbidities, including coronary artery disease (CAD), onco-haematologic disease, diabetes and hypertension. We collected also the clinical characteristics of Sars-CoV-2 at presentation, the ratio of arterial oxygen partial pressure to fractional inspired oxygen ( $\mathrm{PaO} 2 / \mathrm{FiO} 2)$ laboratory findings including full blood count (FBC), inflammatory indexes (procalcitonin, PCT, CRP, ferritin, IL-6), lactate dehydrogenase $(\mathrm{LDH})$ and radiological $\mathrm{CT}$ findings. We analysed SARS-CoV-2 active cancer patients focusing on the type of malignancy (solid tumour vs haematologic disease), the diagnosis (lung cancer, genitourinary-GU cancer, gastrointestinal-Gl cancer, breast cancer and other)), the extent (localised vs metastatic) and the status of disease at the COVID-19 diagnosis, i.e. progressive disease (PD) vs non-PD (CR/PR/ $\mathrm{SD} / \mathrm{NED}$ ). Active cancer was defined by the presence of localised or metastatic disease at the time of the viral infection, despite the received oncological treatment. Patients undergoing radical surgery or radical radio-chemotherapy within 4 weeks from COVID-19 diagnosis were also included in the analysis. Conversely, patients with a history of cancer or on adjuvant hormonal treatment were not considered in the cancer subgroup. Surrogate endpoints for COVID19 survival included the length of hospitalisation, the ICU admission and the in-hospital fatality rate. The absence of prospective informed consent was waived by the Ethics Committee due to the emergency situation of the clinical scenario of the current pandemic.

Statistical analyses

Demographic and clinical characteristics were summarised as number and percentage or as median and range. Differences in distribution were estimated using the Chi-square or the Fisher exact test (when appropriate). Patients survival was calculated from the hospitalisation until death or discharge. Survival curves were generated using the Kaplan-Meier method. Median follow-up was estimated using the inverse Kaplan-Meier method. Differences between groups were evaluated using the log-rank test. The Cox proportional hazard regression model was used to calculate the hazard ratios (HRs) and their 95\% confidence intervals $(\mathrm{Cl})$ in univariate and multivariate analysis. ICU was included in the model as a time-dependent variable starting from the first day of ICU admission. A propensity score matching was performed to estimate the effect of cancer by accounting for the covariates statistically significant in the multivariable model. For each cancer patient, four comparable patients were selected in the non-cancer population (1:4 ratio). All the reported $p$-values were two-sided. All analyses were carried out with the SAS software v. 9.4.

\section{RESULTS}

Demographics and clinical features

We reported on 557 consecutive COVID-19 patients admitted at our Institution between February 27 and May 20, 2020, of whom 46 had active cancer (8\%). Demographics, clinical and laboratory findings of COVID-19 patients are reported in Table 1. Most 


\begin{tabular}{|c|c|c|c|c|}
\hline Characteristics & $\mathrm{HR}$ & Lower $95 \% \mathrm{Cl}$ & Upper $95 \% \mathrm{Cl}$ & $p$-value \\
\hline \multicolumn{5}{|l|}{ Gender } \\
\hline Male vs female & 1.24 & 0.86 & 1.79 & 0.259 \\
\hline \multicolumn{5}{|l|}{ Age } \\
\hline Continuous values & 1.08 & 1.07 & 1.10 & $<0.001$ \\
\hline \multicolumn{5}{|l|}{ BMI } \\
\hline Continuous values & 0.98 & 0.94 & 1.02 & 0.312 \\
\hline$\geq 30$ & - & & & \\
\hline$<30$ & 0.66 & 0.40 & 1.03 & 0.113 \\
\hline \multicolumn{5}{|l|}{ Diabetes } \\
\hline No & - & & & \\
\hline Yes & 1.54 & 1.06 & 2.22 & 0.023 \\
\hline \multicolumn{5}{|l|}{ Hypertension } \\
\hline No & - & & & \\
\hline Yes & 1.68 & 1.15 & 2.45 & 0.008 \\
\hline \multicolumn{5}{|l|}{ Dysplidaemia } \\
\hline No & - & & & \\
\hline Yes & 1.63 & 1.12 & 2.37 & 0.011 \\
\hline \multicolumn{5}{|l|}{ CAD } \\
\hline No & - & & & \\
\hline Yes & 2.85 & 1.98 & 4.09 & $<0.001$ \\
\hline \multicolumn{5}{|l|}{ Cancer } \\
\hline No & - & & & \\
\hline Yes & 2.79 & 1.76 & 4.42 & $<0.001$ \\
\hline \multicolumn{5}{|l|}{ Lymphocytes } \\
\hline$<1000$ & - & & & \\
\hline$\geq 1000$ & 0.53 & 0.36 & 0.77 & 0.001 \\
\hline \multicolumn{5}{|l|}{ LDH } \\
\hline$<248$ & - & & & \\
\hline$\geq 248$ & 2.85 & 1.57 & 5.18 & 0.001 \\
\hline \multicolumn{5}{|l|}{ IL-6 } \\
\hline No & - & & & \\
\hline Yes & 0.71 & 0.36 & 1.38 & 0.306 \\
\hline \multicolumn{5}{|l|}{ PCT } \\
\hline$<0.5$ & - & & & \\
\hline$\geq 0.5$ & 3.24 & 2.27 & 4.62 & $<0.001$ \\
\hline \multicolumn{5}{|l|}{ CRP } \\
\hline \multicolumn{5}{|l|}{$<0.5$} \\
\hline$\geq 0.5$ & 3.59 & 0.50 & 25.68 & 0.203 \\
\hline \multicolumn{5}{|l|}{ Ferritin } \\
\hline \multicolumn{5}{|l|}{$<336.2$} \\
\hline$\geq 336.2$ & 1.32 & 0.83 & 2.09 & 0.238 \\
\hline \multicolumn{5}{|l|}{ Smoking } \\
\hline \multicolumn{5}{|l|}{ No/former } \\
\hline Yes & 3.17 & 2.03 & 4.95 & $<0.001$ \\
\hline NLR & & & & \\
\hline & 1.03 & 1.01 & 1.04 & $<0.001$ \\
\hline $\mathrm{PaO} 2 / \mathrm{FiO} 2$ & & & & \\
\hline & 0.99 & 0.99 & 1.00 & $<0.001$ \\
\hline Ground glass & & & & \\
\hline No & & & & \\
\hline Yes & 1.43 & 0.59 & 3.51 & 0.431 \\
\hline Pulmonary consolidati & & & & \\
\hline No & - & & & \\
\hline Yes & 1.42 & 0.99 & 2.05 & 0.60 \\
\hline Pleural effusion & & & & \\
\hline No & - & & & \\
\hline
\end{tabular}

\begin{tabular}{|llllr}
\hline Table 2. continued & & & & \\
\hline Characteristics & HR & Lower $95 \% \mathrm{Cl}$ & Upper $95 \% \mathrm{Cl}$ & $p$-value \\
\hline Yes & 1.10 & 0.75 & 1.60 & 0.625 \\
Pulmonary adenopathy & & & & \\
No & - & & 3.51 & 0.431 \\
Yes & 1.43 & 0.59 & & \\
\hline CAD coronary artery disease, $B M I$ body mass index, $C l$ confidence interval, \\
$L D H$ lactate dehydrogenase, & $I L-6$ interleukin-6, $P C T$ procalcitonin, $N L R$ \\
neutrophil-lymphocyte ratio. & &
\end{tabular}

Table 3. Multivariable analysis in the whole hospitalised population.

\begin{tabular}{llllr}
\hline Variable & HR & Lower 95\% Cl & Upper 95\% Cl & $p$-value \\
\hline Age (continuous values) & 1.08 & 1.06 & 1.1 & $<0.001$ \\
Cancer vs non-cancer & 2.26 & 1.39 & 3.657 & 0.001 \\
LDH (>248 vs $<248 \mathrm{U} / \mathrm{L})$ & 2.42 & 1.276 & 4.603 & $<0.007$ \\
PaO2/FiO2 & 0.99 & 0.994 & 0.998 & 0.001 \\
PCT (>0.5 vs $<0.5 \mathrm{ng} / \mathrm{mL})$ & 2.21 & 1.506 & 3.234 & $<0.001$ \\
CAD vs no CAD & 1.67 & 1.128 & 2.465 & 0.01 \\
Smoking vs no smoking & 1.65 & 1.02 & 2.679 & 0.041 \\
\hline CAD coronary artery disease, Cl confidence interval, LDH lactate dehy- \\
drogenase, PCT procalcitonin.
\end{tabular}

patients were men $(n=375,67 \%)$, with a median age of 67 (range 27-96). Forty-eight patients (9\%) were active smokers. With respect to comorbidities, 137 had diabetes (25\%), 284 hypertension (51\%), 114 CAD (20\%) and 122 dyslipidaemia (22\%). Comparing oncologic $(n=46)$ and non-oncologic patients $(n=511)$, the former were older (mean age 71 vs $65 ; p=0.012)$, more often smokers $(20 \%$ vs $8 \% ; p=0.009)$ and with higher neutrophil-to-lymphocyte ratio (NLR) (mean 13.3 vs $8.2 ; p=0.046$ ). The mean value of $\mathrm{PaO} 2 / \mathrm{FiO} 2$ recorded in the emergency department was 283 in cancer patients vs 292 in non-cancer patients, which resulted not statistically significant $(p=0.558$, Table 1).

Survival analysis

With a median follow-up of 12 days (range 0-76), 126 patients died $(23 \%)$, of whom 23 were cancer patients. Considering the cancer patients cohort, the fatality rate was $50 \%(\mathrm{Cl} 95 \%$ : $34.9 ; 65.1)$, whereas in the non-cancer subgroup was $20.2 \%(\mathrm{Cl}$ $95 \%: 16.8 ; 23.9)$. Factors influencing the outcome in the univariable evaluation were age, hypertension, dyslipidaemia, diabetes, CAD, cancer, lymphocyte count, LDH level, PCT, smoking, NLR, PaO2/ FiO2. Table 2 shows the survival-related hazard ratios (HR), 95\% confidence interval $(\mathrm{Cl})$ and $p$-values. Multivariable Cox regression model (Table 3) confirmed the impact of active cancer (HR: 2.26, $95 \%, \mathrm{Cl}: 1.39 ; 3.66, p=0.001$, Fig. 1$)$ adjusted for age (HR continuous: $1.08, p<0.001), \mathrm{LDH}\left(\mathrm{HR}_{\mathrm{LDH}>248}: 2.42, p<0.007\right), \mathrm{PaO} 2 / \mathrm{FiO} 2$ (HR continuous: $1.00, p<0.001)$, PCT (HR $\left.\mathrm{HCT}_{\mathrm{P}} 0.5: 2.21, p<0.001\right), \mathrm{CAD}$ $\left(\mathrm{HR}_{\text {yes }}\right.$ : $\left.1.67, p=0.010\right)$ and cigarette smoking $\left(\mathrm{HR}_{\text {yes }}\right.$ : 1.65, $p=0.041)$ as independent statistically significant predictors of outcome. Propensity score matching performed considering multivariable statistically significant factors, demonstrated in the active cancer population a $1.92 \times$ risk of death compared to the non-cancer population, irrespectively of ICU admission $(\mathrm{Cl} 95 \%$ : $1.15 ; 3.21, p=0.013$ ) (Table 4) 1). Indeed, ICU admission was included as a time-dependent variable in the model $\left(\mathrm{HR}_{\text {yes }}: 0.55, \mathrm{Cl}\right.$ 95\%: $0.25 ; 1.20, p=0.131$ ) but did not influence the outcome. Hence, we registered a median OS of 14 days for cancer patients 


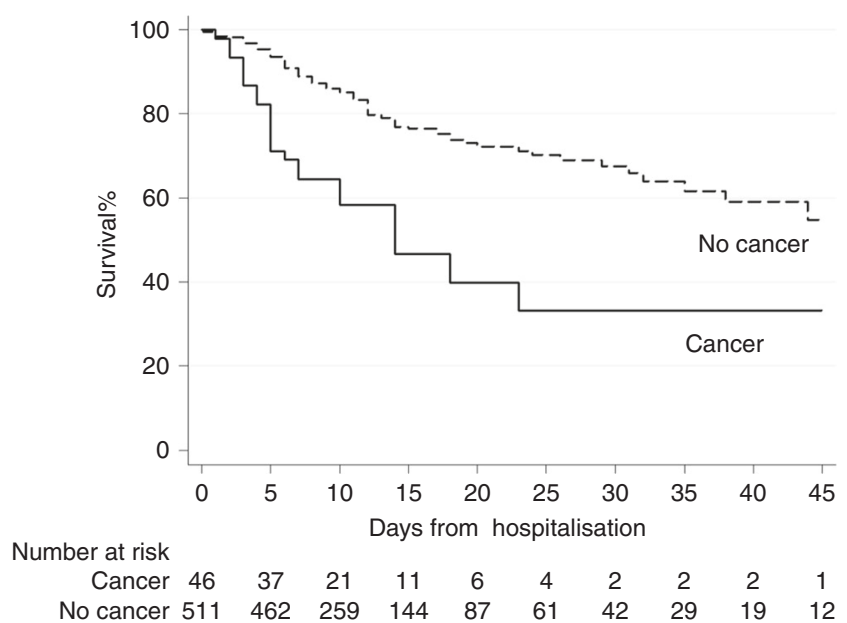

Fig. 1 COVID-19 survival in cancer and non-cancer patients. Cancer patients showed a poorer COVID-19 survival (HR: 2.26; Cl 95\%: 1.39;3.66, $p=0.001$ ).

\begin{tabular}{|c|c|c|c|c|c|}
\hline \multirow[b]{3}{*}{ All } & \multicolumn{2}{|c|}{ Non-cancer } & \multicolumn{2}{|c|}{ Cancer } & \multirow[t]{3}{*}{$p$-value } \\
\hline & $N$ & $\%$ & $N$ & $\%$ & \\
\hline & \multicolumn{2}{|l|}{180} & \multicolumn{2}{|l|}{45} & \\
\hline \multicolumn{6}{|c|}{ Age (continuous values, mean $\mathrm{Cl} 95 \%$ ) } \\
\hline & 69.5 & $67.5 ; 71.5$ & 70.6 & $67.0 ; 74.2$ & 0.614 \\
\hline \multicolumn{6}{|l|}{ Diabetes } \\
\hline No & 138 & 76.67 & 34 & 75.56 & \multirow[t]{2}{*}{0.875} \\
\hline Yes & 42 & 23.33 & 11 & 24.44 & \\
\hline \multicolumn{6}{|l|}{ Hypertension } \\
\hline No & 105 & 58.33 & 25 & 55.56 & \multirow[t]{2}{*}{0.736} \\
\hline Yes & 75 & 41.67 & 20 & 44.44 & \\
\hline \multicolumn{6}{|l|}{ Dysplidemia } \\
\hline No & 138 & 76.67 & 33 & 73.33 & \multirow[t]{2}{*}{0.64} \\
\hline Yes & 42 & 23.33 & 12 & 26.67 & \\
\hline \multicolumn{6}{|l|}{ CAD } \\
\hline No & 136 & 75.56 & 32 & 71.11 & \multirow[t]{2}{*}{0.54} \\
\hline Yes & 44 & 24.44 & 13 & 28.89 & \\
\hline \multicolumn{6}{|l|}{ LDH (U/L) } \\
\hline$<248$ & 40 & 22.22 & 11 & 24.44 & \multirow[t]{2}{*}{0.75} \\
\hline$\geq 248$ & 140 & 77.78 & 34 & 75.56 & \\
\hline \multicolumn{6}{|l|}{ PCT (ng/mL) } \\
\hline$<0.5$ & 124 & 68.89 & 29 & 64.44 & \multirow[t]{2}{*}{0.568} \\
\hline$\geq 0.5$ & 56 & 31.11 & 16 & 35.56 & \\
\hline \multicolumn{6}{|l|}{ Smoking } \\
\hline No ex & 149 & 82.78 & 36 & 80.00 & \multirow[t]{2}{*}{0.663} \\
\hline Yes & 31 & 17.22 & 9 & 20.00 & \\
\hline \multicolumn{6}{|l|}{$\mathrm{PaO} 2 / \mathrm{FiO} 2$} \\
\hline (mean $\mathrm{Cl} 95 \%)$ & 284.8 & $272 ; 297.5$ & 280.9 & $251 ; 310.8$ & 0.795 \\
\hline
\end{tabular}

compared to 35 days for other patients (Fig. 1). Considering the cancer cohort, we did not observe any difference between solid and haematologic tumours (HR 1.04, Cl 95\%: 0.41;2.65, $p=0.931$, Fig. 2a). Noteworthy, lung cancer patients showed a poor prognosis compared to other cancer diagnosis (Fig. 2b), albeit not statistically significant (HR: 1.93, Cl 95\%: 0.79;4.71, $p=0.148 ; 7$ vs 14 median days of hospitalisation, $p=0.128$ ). A full comparison in survival probability between tumour types is available online as Supplementary Material (Supplementary. Material 1). We did not report any differences in outcome between localised and metastatic disease (HR: 0.8; Cl 95\%: 0.31;2.08, $p=0.649$, Fig. 2c) but, considering disease status at COVID-19 diagnosis, we reported a significantly worse COVID-19 outcome in patients with progressive disease (PD) compared to non-PD patients (HR: 2.931, $\mathrm{Cl} 95 \% 1.2 ; 7.14, p=0.018$, Fig. 2d). Extent of disease and delivered treatment are reported in Table 5 for each tumour type.

\section{DISCUSSION}

In our retrospective analysis, we have reported that both the epidemiology and clinical presentation of COVID-19 in active cancer patients in Italy are similar to the non-cancer population This notwithstanding, we observed how the natural course of the COVID-19, as well as the final outcome, are significantly worse in cancer patients, resulting in an almost double fatality rate (HR: 1.92 , propensity score result). Working at an Institution extensively involved in the COVID-19 emergency, we had the opportunity to evaluate a large number of admitted patients, collecting detailed clinical, laboratory and radiological data, including comorbidities such as cancer and related treatment. ${ }^{9}$ In the current analysis, the demographics and clinical characteristics of cancer and noncancer patients were similar including $\mathrm{BMI}^{28} \mathrm{~A}$ male predominance in COVID-19, possibly explained by differences in innate and adaptive immunity, has been confirmed. ${ }^{29}$ At the time of COVID-19 diagnosis, the clinical presentation was similar among the two cohorts of patients. Unexpectedly, the respiratory impairment evaluated through $\mathrm{PaO} 2 / \mathrm{FiO}_{2}$, as well as chest CT scan performed in the Emergency Department did not show any significant differences. As we had previously published, ${ }^{9}$ active cancer and relative treatments, including chemotherapy, immunotherapy and targeted therapies, did not result in an increased risk of Sars-CoV-2 infection. ${ }^{9}$ The lack of standardised criteria to define active cancer patients might have been responsible for the initial worries regarding the reported high incidence of cancer patients among Sars-CoV-2 infected individuals. ${ }^{30,31}$ A detailed analysis of published case-series showed most of them were likely patients with a history of cancer, rather than with active cancer.

Even if the risk for Sars-CoV-2 infection and the clinical presentation of COVID-19 are similar, it does result in a double mortality rate in cancer patients compared to non-cancer patients in a multivariable analysis ( $\left.\mathrm{HR}_{\text {active: }}: 2.21\right)$. Unexpectedly, we did not notice any differences between solid and haematologic cancers. However, focusing on the histological diagnosis, we observed that only few patients were affected by aggressive blood diseases (e.g. AML or NHL) rather than chronic, indolent disease that would arguably affect the course of the infection. Several efforts have been made to decipher the negative influence of cancer on COVID-19 outcome. Our results confirm the higher mortality rate among cancer patients compared to nononcological populations. ${ }^{6,10-12,32}$ In stark contrast with such reports, a matched cohort study from the Presbyterian Hospital (New York, USA) reported similar outcomes in cancer and noncancer COVID-19 patients. Unlike previous studies, the authors included in the cancer subgroup, either patients who received active cancer treatment and patients on follow-up who received the last oncologic therapy up to 6 months before the admission for COVID-19. We adopted more stringent criteria including in the cancer cohort only those patients with localised or metastatic disease who received diagnosis or therapy within 4 weeks before the admission for COVID-19. Several factors could play a role in the fatal course of COVID-19 in patients with active cancer. First of all, cancer-related inflammation, as well as the associated 
a

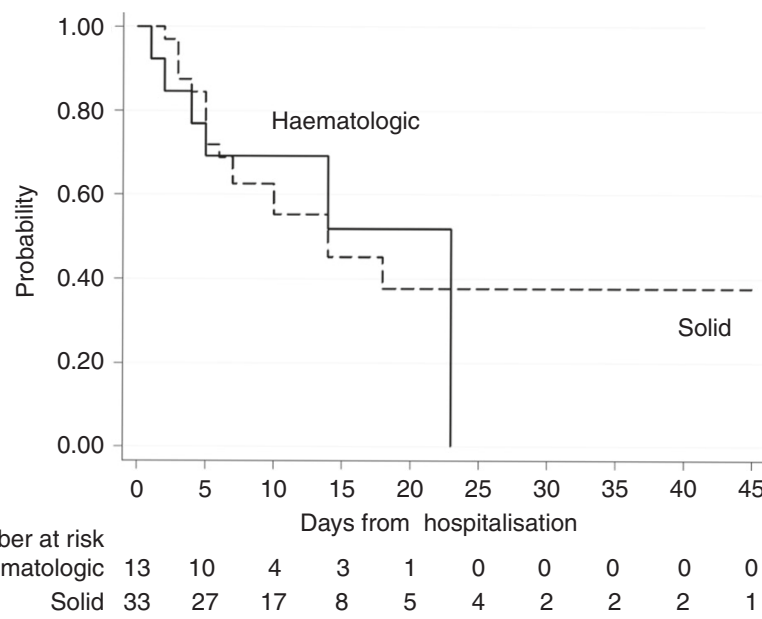

C

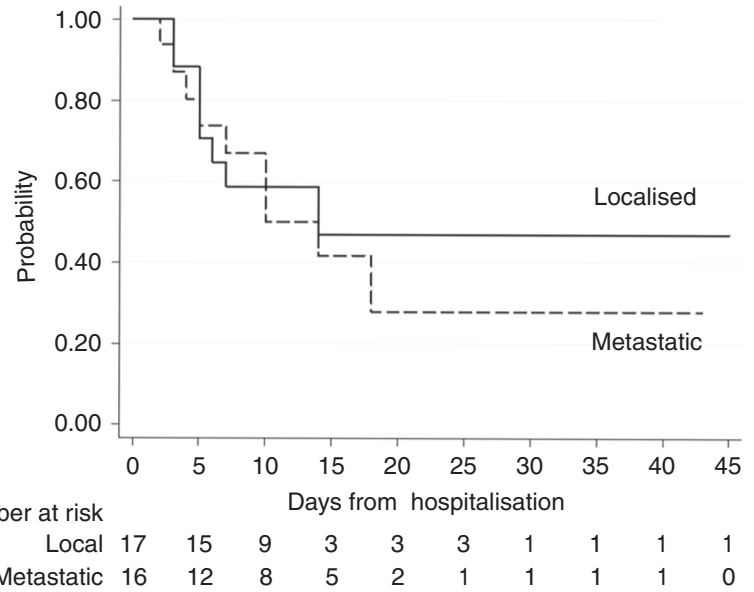

b

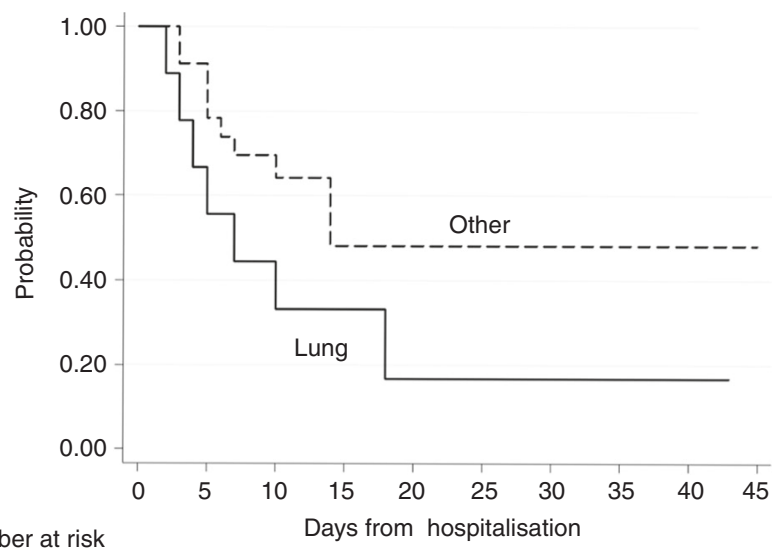

Number at risk

Lung $90 \begin{array}{lllllllll}6 & 4 & 3 & 1 & 1 & 1 & 1 & 1 & 0\end{array}$

d

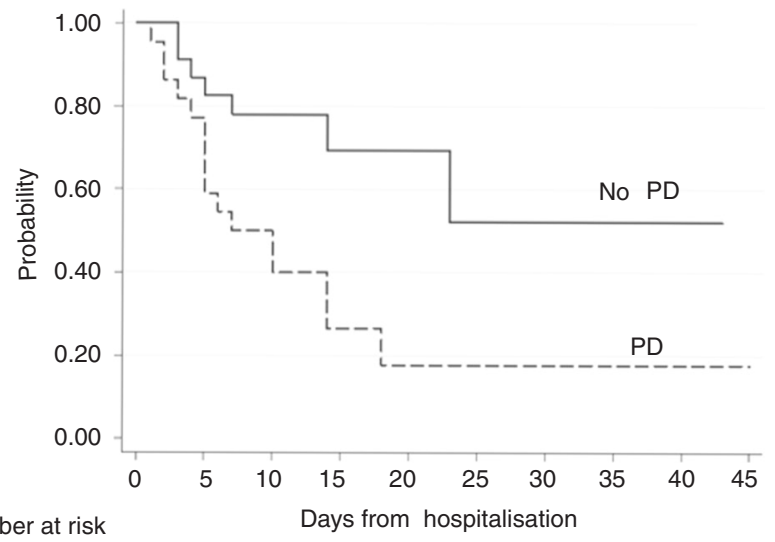

Fig. 2 COVID-19 survival stratified by subtype of cancer and status of disease. a solid cancer vs haematologic cancer; $\mathbf{b}$ tumour type (lung vs other); c localised vs metastatic disease; $\mathbf{d}$ disease status at COVID-19 diagnosis (PD vs non-PD cancer patients).

\begin{tabular}{|c|c|c|c|c|c|c|c|c|c|c|c|c|c|}
\hline Diagnosis & Patients $(n=46)$ & Localised & Metastatic/Systemic & $\mathrm{PD}$ & non-PD & NED & Naive & Surgery & RT & CT & $\lg$ & Target & Hormone \\
\hline Solid tumour & 33 & 17 & 16 & 19 & 10 & 4 & 15 & 3 & 4 & 8 & 2 & 1 & 4 \\
\hline Lung & 9 & 2 & 7 & 6 & 2 & 1 & 5 & 1 & 1 & 1 & 1 & 0 & 0 \\
\hline GI & 10 & 8 & 2 & 7 & 1 & 2 & 6 & 2 & $1^{\mathrm{a}}$ & $2^{\mathrm{a}}$ & 0 & 0 & 0 \\
\hline Other $^{c}$ & 5 & 3 & 2 & 2 & 3 & 0 & 1 & 0 & $2^{\mathrm{a}}$ & $3^{\mathrm{a}}$ & 0 & 0 & 1 \\
\hline Haematologic & 13 & 0 & 13 & 3 & 8 & 2 & 6 & 0 & 1 & 5 & 2 & 0 & 0 \\
\hline AML & 3 & 0 & 3 & 3 & 0 & 0 & 2 & 0 & 0 & 1 & 0 & 0 & 0 \\
\hline MDS & 4 & 0 & 4 & 0 & 4 & 0 & 3 & 0 & 0 & 1 & 0 & 0 & 0 \\
\hline LLC & 3 & 0 & 3 & 0 & 3 & 0 & 3 & 0 & 0 & 0 & 0 & 0 & 0 \\
\hline LMC & 1 & 0 & 1 & 0 & 0 & 1 & 0 & 0 & 0 & $1^{a, b}$ & $1^{\mathrm{b}}$ & 0 & 0 \\
\hline
\end{tabular}


prothrombotic status typically related to uncontrolled solid or haematologic cancer growth, could be responsible for the unfavourable prognosis in hospitalised COVID-19 patients. ${ }^{33-35}$ We suspected also a higher incidence of bacterial co-infection in the oncologic cohort, with a potential detrimental effect on outcome. Still, our study did not support this hypothesis as PCT values were comparable among the two groups. In line with our findings, a recent meta-analysis on 3834 patients showed a low proportion of COVID-19 patients having bacterial co-infection. ${ }^{36}$

Our study has some limitations. We acknowledge that ascribing the ultimate cause of death in cancer patients with COVID-19 is challenging. However, our results highlight that patients with newly diagnosed uncontrolled cancer, as well as progressive disease, are more likely to show a poor prognosis in case of COVID-19 infection, which may be related to an impaired immunological response. A further potential bias might be represented by the availability of intensive care in the ICU in a scenario of limited resources. Despite the low number of events, we proved by the propensity score analysis that admission to the ICU did not account for differences in outcome between the two cohorts of patients. Finally, the mono-institutional nature of our study prevented us from recruiting a large number of patients, thus limiting our analysis, especially in some specific histiotypes (e.g. aggressive blood disease). In conclusion, despite a comparable clinical presentation, we report a near two-fold increase in death rate between cancer and non-cancer COVID-19 patients admitted at a tertiary referral Italian hospital. Our data suggest uncontrolled cancer diagnosis to independently impact on clinical outcome regardless of other clinical characteristics including preexisting comorbidities. To date, the understanding of the natural course of COVID-19 in active cancer patients is limited, and requires further cooperative efforts to be unfolded. Considering the vulnerable status of patients with active cancer in the current pandemic, state-ofthe art cancer care should guarantee the continuity of treatment along with a direct engagement of multidisciplinary stakeholders to meet patients' needs. ${ }^{37,38}$

\section{ACKNOWLEDGEMENTS}

Not applicable.

\section{AUTHOR CONTRIBUTIONS}

A.F.B., M.C.-Drafting of manuscript, Data Interpretation, Study Concept; A.F.B., N.G., A.M., U.C., A.S.-Drafting of manuscript, Data Interpretation; M.C., A.S., M.A., V.L.Q.Drafting of manuscript, Study Supervisors; A.D., A.F.B., A.M., M.C.-Drafting of manuscript, Data collection; L.G.-Drafting of manuscript, Statistical analysis.

\section{ADDITIONAL INFORMATION}

Ethics approval and consent to participate Ethics approval was provided by the local ethics committee of Humanitas Clinical and Research Center; the study was performed in accordance with the Declaration of Helsinki. Consent to participate was obtained from the patients involved in the study.

Consent to publish Consent for publication have be obtained from the patients involved in the study.

Data availability The datasets generated during and/or analysed during the current study are available from the corresponding author on reasonable request.

Competing interests The authors declare no competing interests.

Funding information The authors received no specific funding for this work.

The online version contains supplementary material available at https://doi.org/ 10.1038/s41416-021-01396-9.

Publisher's note Springer Nature remains neutral with regard to jurisdictional claims in published maps and institutional affiliations.

\section{REFERENCES}

1. Zhang, L., Zhu, F., Xie, L., Wang, C., Wang, J., Chen, R. et al. Clinical characteristics of COVID-19-infected cancer patients: a retrospective case study in three hospitals within Wuhan, China. Ann. Oncol. 31, 894-901 (2020).

2. Kutikov, A., Weinberg, D. S., Edelman, M. J., Horwitz, E. M., Uzzo, R. G. \& Fisher, R. I. A war on two fronts: cancer care in the time of COVID-19. Ann. Intern. Med. 172, 756-758 (2020).

3. Xia, Y., Jin, R., Zhao, J., Li, W. \& Shen, H. Risk of COVID-19 for patients with cancer. Lancet Oncol. 21, e180 (2020).

4. Sidaway, P. COVID-19 and cancer: what we know so far. Nat. Rev. Clin. Oncol. 17, 336 (2020).

5. Lee, L. Y., Cazier, J.-B., Angelis, V., Arnold, R., Bisht, V., Campton, N. A. et al. COVID19 mortality in patients with cancer on chemotherapy or other anticancer treatments: a prospective cohort study. Lancet 395, 1919-1926 (2020).

6. Ofori-Asenso, R., Ogundipe, O., Agyeman, A. A., Chin, K. L., Mazidi, M., Ademi, Z. et al. Cancer is associated with severe disease in COVID-19 patients: a systematic review and meta-analysis. Ecancermedicalscience 14, 1047 (2020).

7. Yang, K., Sheng, Y., Huang, C., Jin, Y., Xiong, N., Jiang, K. et al. Clinical characteristics, outcomes, and risk factors for mortality in patients with cancer and COVID-19 in Hubei, China: a multicentre, retrospective, cohort study. Lancet Oncol. 21, 904-913 (2020)

8. Mei, H., Dong, X., Wang, Y., Tang, L. \& Hu, Y. Managing patients with cancer during the COVID-19 pandemic: frontline experience from Wuhan. Lancet Oncol. 21, 634-636 (2020).

9. Bertuzzi, A. F., Marrari, A., Gennaro, N., Cariboni, U., Ciccarelli, M., Giordano, L. et al. Low incidence of SARS-CoV-2 in patients with solid tumours on active treatment: an observational study at a Tertiary Cancer Centre in Lombardy, Italy. Cancers (Basel). 12, 2352 (2020).

10. Gosain, R., Abdou, Y., Singh, A., Rana, N., Puzanov, I. \& Ernstoff, M. S. C. O. V. I. D.-1. 9. and Cancer: a Comprehensive Review. Curr. Oncol. Rep. 22, 53 (2020).

11. Kuderer, N. M., Choueiri, T. K., Shah, D. P., Shyr, Y., Rubinstein, S. M., Rivera, D. R. et al. Clinical impact of COVID-19 on patients with cancer (CCC19): a cohort study. Lancet 395, 1907-1918 (2020).

12. ElGohary, G. M., Hashmi, S., Styczynski, J., Kharfan-Dabaja, M. A., Alblooshi, R. M., de la Cámara, R. et al. The risk and prognosis of COVID-19 infection in cancer patients: a systematic review and meta-analysis. Hematol. Oncol. Stem Cell Ther. (2020). in press.

13. ASCO Statement on Novel Coronavirus (COVID-19). ASCO Annual Meeting. https:// meetings.asco.org/am/asco-statement-novel-coronavirus-covid-19 (2020).

14. COVID-19 and Cancer. ESMO. https://www.esmo.org/covid-19-and-cancer (2020).

15. Burki, T. K. Cancer guidelines during the COVID-19 pandemic. Lancet Oncol. 21, 629-630 (2020).

16. Giuliani, J. \& Bonetti, A. Cancer prevales on COVID-19: To maintain high quality standard concerning diagnosis and oncological care even during a pandemic. J. Med. Virol. 93, 118-119 (2020).

17. de Joode, K., Dumoulin, D. W., Engelen, V., Bloemendal, H. J., Verheij, M., van Laarhoven, H. W. M. et al. Impact of the coronavirus disease 2019 pandemic on cancer treatment: the patients' perspective. Eur. J. Cancer 136, 132-139 (2020).

18. Al-Quteimat, O. M. \& Amer, A. M. The impact of the COVID-19 pandemic on cancer patients. Am. J. Clin. Oncol. 43, 452-455 (2020).

19. Ciążyńska, M., Pabianek, M., Szczepaniak, K., Ułańska, M., Skibińska, M., Owczarek, W. et al. Quality of life of cancer patients during coronavirus disease (COVID-19) pandemic. Psychooncology 1-3 (2020).

20. Richards, M., Anderson, M., Carter, P., Ebert, B. L. \& Mossialos, E. The impact of the COVID-19 pandemic on cancer care. Nat. Cancer 1, 565-567 (2020).

21. Omarini, C., Maur, M., Luppi, G., Narni, F., Luppi, M., Dominici, M. et al. Cancer treatment during the coronavirus disease 2019 pandemic: do not postpone, do it! Eur. J. Cancer 133, 29-32 (2020).

22. Oh, W. K. COVID-19 infection in cancer patients: early observations and unanswered questions. Ann. Oncol. 31, 838-839 (2020).

23. Poortmans, P. M., Guarneri, V. \& Cardoso, M.-J. Cancer and COVID-19: what do we really know? Lancet 395, 1884-1885 (2020).

24. Allegra, A., Pioggia, G., Tonacci, A., Musolino, C. \& Gangemi, S. Cancer and SARS-CoV2 infection: diagnostic and therapeutic challenges. Cancers (Basel). 12, 1481(2020).

25. Venkatesulu, B. P. Chandrasekar, V. T, Girdhar, P. Advani, P. Sharma, A. Elumalai, T. et al. A systematic review and meta-analysis of cancer patients affected by a novel coronavirus. medRxiv (2020).

26. Li, Q., Chen, L., Li, Q., He, W., Yu, J., Chen, L. et al. Cancer increases risk of inhospital death from COVID-19 in persons $<65$ years and those not in complete remission. Leukemia 34, 2384-2391 (2020).

27. Jyotsana, N. \& King, M. R. The impact of COVID-19 on cancer risk and treatment. Cell Mol. Bioeng. 13, 285-291 (2020).

28. Huang, Y., Lu, Y., Huang, Y.-M., Wang, M., Ling, W., Sui, Y. et al. Obesity in patients with COVID-19: a systematic review and meta-analysis. Metab. Clin. Exp. 113, 154378 (2020) 
29. Takahashi, T., Ellingson, M. K., Wong, P., Israelow, B., Lucas, C., Klein, J. et al. Sex differences in immune responses that underlie COVID-19 disease outcomes. Nature 588, 315-320 (2020).

30. Curigliano, G. Cancer patients and risk of mortality for COVID-19. Cancer Cell. 38 161-163 (2020)

31. Grasselli, G., Zangrillo, A., Zanella, A., Antonelli, M., Cabrini, L., Castelli, A. et al. Baseline characteristics and outcomes of 1591 patients infected with SARS-CoV-2 admitted to ICUs of the Lombardy Region, Italy. JAMA 323, 1574-1581 (2020).

32. Pinato, D. J., Zambelli, A., Aguilar-Company, J., Bower, M., Sng, C., Salazar, R. et al. Clinical portrait of the SARS-CoV-2 epidemic in European cancer patients. Cancer Discov. 10, 1465-1474 (2020).

33. Lodigiani, C., lapichino, G., Carenzo, L., Cecconi, M., Ferrazzi, P., Sebastian, T. et al. Venous and arterial thromboembolic complications in COVID-19 patients admitted to an academic hospital in Milan, Italy. Thromb. Res. 191, 9-14 (2020).
34. Singhania, N., Bansal, S., Nimmatoori, D. P., Ejaz, A. A., McCullough, P. A., Singhania, G. Current overview on hypercoagulability in COVID-19. Am. J. Cardiovasc. Drugs 4, 1-11 (2020).

35. Abou-Ismail, M. Y., Diamond, A., Kapoor, S., Arafah, Y. \& Nayak, L. The hypercoagulable state in COVID-19: Incidence, pathophysiology, and management. Thromb. Res. 194, 101-115 (2020).

36. Lansbury, L., Lim, B., Baskaran, V. \& Lim, W. S. Co-infections in people with COVID-19: a systematic review and meta-analysis. J. Infect. 81, 266-275 (2020).

37. Bertuzzi, A. F., Gennaro, N., Marrari, A. \& Santoro, A. The blurred line between the art and science of medicine. Radiother. Oncol. 4, 61 (2020).

38. Rocque, G., Miller-Sonnet, E., Balch, A., Stricker, C., Seidman, J., Stiles, S. et al. Engaging multidisciplinary stakeholders to drive shared decision-making in oncology. J. Palliat. Care. 34, 29-31 (2019). 